\title{
Pair bonding in spotted poison frogs
}

$\mathrm{O}$ nce thought to interact very little with conspecifics, amphibians are now known to have elaborate mating systems ${ }^{1}$. Pair bonding, defined as a social and copulatory relationship between two individuals that share some aspect of offspring rearing (K. Johnson and N. Burley, manuscript in preparation), has not previously been reported to occur in amphibians ${ }^{1}$, although it has been suggested from observations of captive animals ${ }^{2}$. I report here that the spotted poison frog, Dendrobates vanzolinii, an Amazon rainforest species, forms pair bonds and provides extended biparental care of the young under natural conditions, similar to some birds and mammals.

The poison-frog family Dendrobatidae, which is found in rainforests or cloud forests from southern Nicaragua to southern Brazil and Bolivia ${ }^{3}$, comprises about 165 species, classified in six genera. Nearly all species in the family have parental care of terrestrial eggs and tadpoles ${ }^{3}$. Parental care is more advanced in Dendrobates, in which several species feed their tadpoles unfertilized (nutritive) eggs ${ }^{4,5}$.

During March and April 1996, I studied the social behaviour of $D$. vanzolinii in lowland tropical forest in the state of Acre, Brazil (latitude, $8^{\circ} 16^{\prime} \mathrm{S}$; longitude, $72^{\circ} 46^{\prime}$ W). Individual frogs can easily be recognized because each one has a unique pattern of bright yellow spots and/or short lines on a black background. I observed 12 pairs of frogs for a total of 50 hours and $44 \mathrm{~min}$.

Figure 1 shows a pair of frogs of the species $D$. vanzolinii by a cavity in which their tadpole is developing. In addition to rearing a tadpole in the hole, the frogs may subsequently deposit and fertilize an egg which they attach to the inner wall of the cavity above the waterline. The newly developed tadpole is not allowed to slide into the water below because the tadpoles are cannibalistic. Instead, the male transports the new tadpole to another hole suitable for its development. The female does not accompany the male to the new cavity; after a few days he will guide her there by vocal communication.

Male frogs transported single tadpoles to tiny cavities (mean cavity size $3.0 \times 1.7 \mathrm{~cm}$ and $17.9 \mathrm{~cm}$ deep) primarily in saplings and woody vines, at a mean height of roughly $1.2 \mathrm{~m}$ above the forest floor. Pairs cooperated extensively to feed their tadpoles. Males communicated with females by frequently repeated vocalizations. The male's call rate increased in the presence of a female, from $3.7 \pm 0.3(n=5)$ to $7.5 \pm 0.3(n=6)$ calls per min (mean \pm s.e.m.; Mann-Whitney $U$ test, $P \leqslant 0.001)$. If receptive, the female approached the male and began to follow him, sometimes as close

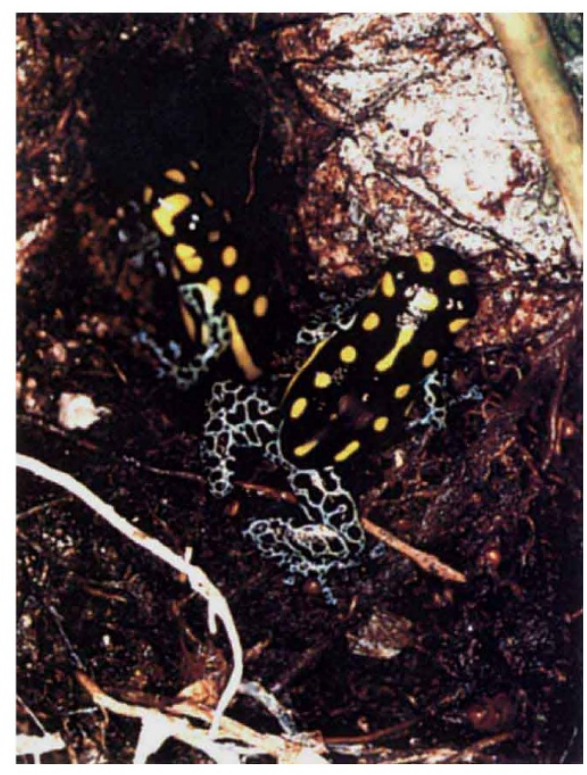

Figure $1 \mathrm{~A}$ pair-bonded male and female D. vanzolinii. The frogs have just emerged from a small cavity in a $5.5-\mathrm{cm}$-diameter sapling where they have undergone courtship behaviour, resulting in the deposition of nutritive (unfertilized) eggs for consumption by their tadpole developing in the hole. The female (left) is sitting at the entrance of the hole; the male has fully emerged and is carrying the pair's newly developed tadpole on his back. In general, dendrobatid frogs are small; male $D$. vanzolinii have a mean ( \pm s.d.) snout-vent length of $17.0 \pm 0.6 \mathrm{~mm}(n=18)$, and females are $18.6 \pm 0.7 \mathrm{~mm}(n=12)$.

behind as $5-10 \mathrm{~cm}$. The male guided the female through vines and small understorey branches to the cavity in which he had previously transported their tadpole. The male and female entered the cavity together, and the male's calls became softer. The pair remained for an extended period (roughly $3 \mathrm{~h}$ ) inside the hole, during which time they underwent courtship behaviour, resulting in the deposition of unfertilized eggs for the tadpole to consume. Of 24 eggs collected, 14 were intact, and only two of these were fertilized. Normally, dendrobatids deposit terrestrial eggs; therefore, eggs deposited in water do not live, even if fertilized.

I never observed females entering holes unless accompanied by a male. Frogs did not feed their young every day, the average interval between feeding being almost 5 days, and I repeatedly saw the same males and females together throughout the study. I saw a male with two females in its territory only once. This cooperation between the same males and females in the same territory to transport and feed their tadpoles is an indication of pair bonding. The length of time a pair remains together is unknown, but there was no evidence that pairs were less strongly bonded at the end of the study compared with the beginning.

Comparative studies are needed to elucidate the evolution of complex social behaviour of Dendrobates that feed their young nutritive eggs. In another lineage of Dendrobates, females, rather than males, transport tadpoles to small leaf axils and return periodically to deposit unfertilized eggs for their tadpoles unaccompanied by a male $e^{4}$. Deception of the female in the lineage with biparental care may have led to the evolution of uniparental care, but currently a well-supported phylogeny of the group does not exist to test this hypothesis.

Janalee P. Caldwell

Oklahoma Museum of Natural History and

Department of Zoology,

University of Oklahoma,

Norman, Oklahoma 73019, USA

e-mail:caldwell@ou.edu

Sullivan, B. K., Ryan, M. J. \& Verrell, P. A. in Amphibian Biolog Vol. 2 (eds Heatwole, H. \& Sullivan, B. K.) Ch. 2 (Surrey Beaty, New South Wales, 1995).

2. Weygoldt, P. Z. Zool. Syst. Evolut. Forsch. 25, 51-67 (1987).

3. Duellman, W. E. \& Trueb, L. Biology of Amphibians (McGraw Hill, New York, 1986).

4. Brust, D. G. J. Herp. 27, 96-98 (1993)

5. Caldwell, J. P. in Neotropical Biodiversity and Conservation (ed. Gibson, A. C.) Ch. 4 (Mildred E. Mathias Botanical Garden, Los Angeles, 1996).

\section{Carbon beads with}

\section{protruding cones}

While experimenting with the formation of vapour-grown carbon fibres, we have produced an apparently novel carbon structure consisting of a unique combination of rough-surfaced beads with protruding smooth cones (see Fig. 1). Transmission electron microscopy reveals that the beads are composed of crumpled sheets of graphene. The cones, in contrast, are composed of relatively straight sheets of graphene aligned parallel to the cone axis: Fig. 1b shows a low-resolution image of the tip of one of the cones. Visible at its centre is the hollow core of the catalytically grown filament, about $6 \mathrm{~nm}$ in diameter, on which the carbon has been deposited. The cone surface cuts across the graphene planes at an angle, leaving exposed plane edges (Fig. 1c).

Despite their dramatically different appearance, several experimental techniques, including X-ray diffraction, microraman spectroscopy and electron energyloss spectroscopy, show that the carbon making up the beads and the cones is 